\title{
Perspective
}

PERSPECTIVE Actualité en histoire de l'art

\section{1 | 2019}

\section{Pays nordiques}

\section{La culture intellectuelle dans la Norvège et l'Islande médiévales}

Intellectual Culture in Medieval Norway and Iceland

Die geistige Kultur im mittelalterlichen Norwegen und Island

La cultura intellettuale nella Norvegia e nell'Islanda Medioevali

La cultura intelectual en Noruega y Islandia medieval

\section{Stefka G. Eriksen}

Traducteur : François Boisivon

\section{(2) OpenEdition}

\section{Journals}

\section{Édition électronique}

URL : http://journals.openedition.org/perspective/13105

DOI : 10.4000/perspective.13105

ISSN : 2269-7721

Éditeur

Institut national d'histoire de l'art

\section{Édition imprimée}

Date de publication : 30 juin 2019

Pagination : 147-164

ISBN : 978-2-917902-49-3

ISSN : $1777-7852$

\section{Référence électronique}

Stefka G. Eriksen, "La culture intellectuelle dans la Norvège et l'Islande médiévales », Perspective [En ligne], 1 | 2019, mis en ligne le 30 décembre 2019, consulté le 01 octobre 2020. URL : http:// journals.openedition.org/perspective/13105; DOI : https://doi.org/10.4000/perspective.13105 


\title{
La culture intellectuelle dans la Norvège et l'Islande médiévales
}

\author{
Stefka G. Eriksen
}

De nombreux chercheurs, déployant autant de perspicacité que de patience, se sont penchés sur la culture intellectuelle médiévale : Jacques Le Goff avec Les Intellectuels au Moyen Âge ${ }^{1}$, Rita Copeland avec Pedagogy, Intellectuals, and Dissent in the Later Middle Ages ${ }^{2}$ ou Ian P. Wei avec Intellectual Culture in Medieval Paris ${ }^{3}$, pour n'en citer que quelques-uns. Le Goff voit dans l'intellectuel celui qui fait métier de penser et de produire de la culture textuelle, s'inscrivant à la fois dans le processus cognitif qui sous-tend l'écriture et dans la production et la rédaction de livres. Il lie l'essor de la culture intellectuelle à celui du développement urbain et notamment de l'université de Paris au XIII siècle. Rita Copeland s'intéresse, quant à elle, à un mouvement intellectuel différent, celui des Lollards, en Angleterre, dans la seconde moitié du XIV ${ }^{e}$ siècle. Elle définit la culture intellectuelle comme une pédagogie et observe comment la condition d'intellectuel peut s'exporter des universités vers le monde du dehors, vers des cercles vernaculaires qui ne font pas profession de penser. Ian P. Wei observe, comme Le Goff, l'université de Paris, mais pour y examiner la coexistence de différents modèles de pensée et de voies vers le savoir. Il définit ainsi la culture intellectuelle comme une combinaison conceptuelle et matérielle et inclut dans le champ de son étude l'œuvre des femmes en dehors de l'université, habituellement considérée à part.

Ces trois livres suffisent à montrer que traiter de la " culture intellectuelle " nécessite d'en décrire les processus, les manières d'enseigner et d'apprendre, les principes institutionnels - notamment la production des livres eux-mêmes ${ }^{4}$ - qui permettent le déploiement intellectuel. Leurs auteurs, quand bien même Le Goff compare l'intellectuel à un artisan, fondent leur analyse de la culture intellectuelle sur la culture écrite.

Les « intellectuels " médiévaux n'utilisaient pourtant pas pour eux-mêmes ce nom générique, préférant se désigner en fonction de leur situation, de leur rôle, de leur profession. En témoigne la diversité des termes désignant l'activité intellectuelle - scolaris, magister, clericus, philosophus, literatus, eruditus, doctor, professor, auctor, artifex-, dont beaucoup nommaient des domaines qui se recouvrent, d'une façon qui contredit parfois notre compréhension intuitive de la culture intellectuelle. Ainsi l'artifex (architecte ou facteur d'art) était-il considéré comme un auctor, œuvrant avec pierres et structures, tandis que 
le prêtre ou le poète étaient des architectes œuvrant avec les mots. Tous les intellectuels pratiquaient la rhétorique, l'art de la persuasion, que ce soit dans leurs écrits, leurs pratiques liturgiques ou dans les édifices qu'ils bâtissaient. La façon dont les intellectuels médiévaux se considéraient eux-mêmes est une invitation à prendre en compte l'ensemble des processus créatifs sous-tendus non seulement par la production de textes et de manuscrits, mais aussi par les réalisations des arts et de l'architecture.

Cet article traite de la culture intellectuelle dans la Norvège et l'Islande médiévales, mais son but n'est pas d'en décrire dans ce contexte particulier le rayonnement ${ }^{5}$; il est plutôt de repérer les courants, les paradigmes qui ont présidé à son étude, de suivre leur évolution, en bref de situer les orientations théoriques et méthodologiques qui ont guidé cette étude. Les recherches analysées ici ne se limitent pas aux travaux portant explicitement sur la culture intellectuelle mais s'étendent à ceux qui examinent les idées et les idéologies ayant conditionné sa production ou permis son expression, empruntant différents supports, textes et documents, manuscrits et enluminures, architecture et arts, monnaies et sceaux. Les sources que j'utiliserai sont pour l'essentiel norvégiennes ou islandaises, considérées comme intégrées au contexte culturel du reste de la Scandinavie et

1. La pierre de Kuli, Trondheim, NTNU University Museum.

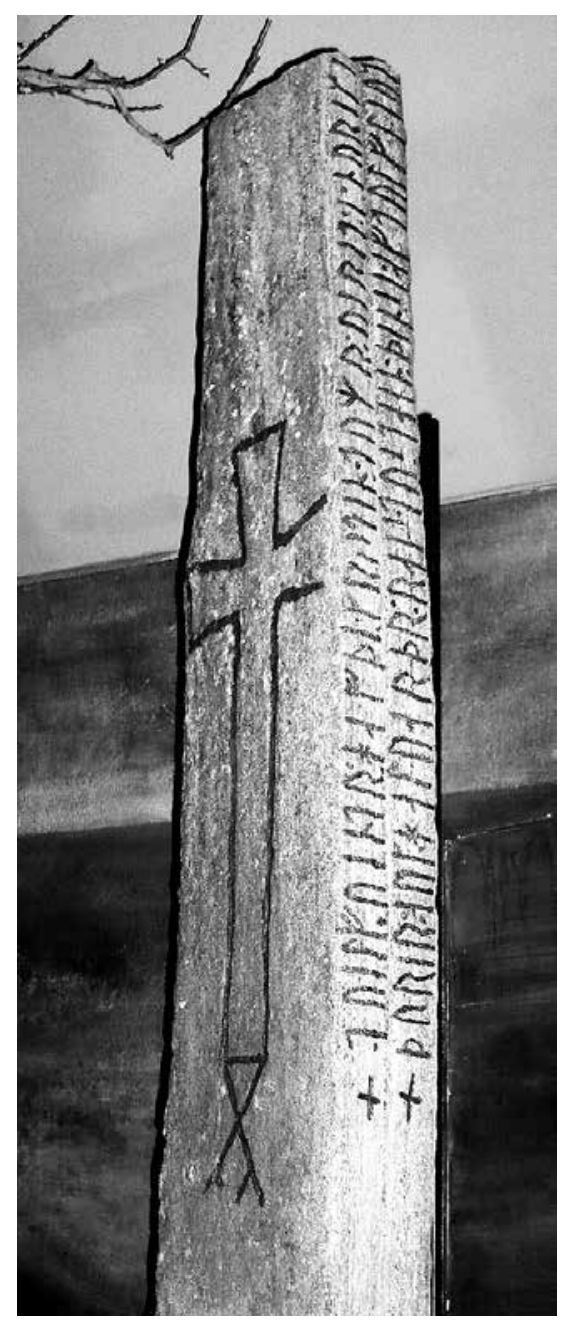
de l'Europe médiévale ${ }^{6}$. Les livres et articles cités ne sont que des exemples parmi d'autres représentant les principaux champs abordés, qui comprennent : les « limites " spatiales et géographiques de la culture intellectuelle ; la textualité, la matérialité et la visualité de la culture intellectuelle, y compris la matérialité de la sainteté ; la culture intellectuelle considérée comme un ensemble de continuités ; les intellectuels et leur identité sociale ; la culture intellectuelle en tant que processus ${ }^{7}$.

\section{Culture intellectuelle globale et locale}

Le premier aspect examiné sera celui des limites géographiques de la culture intellectuelle médiévale. Sont traditionnellement compris dans la Scandinavie médiévale la Norvège, le Danemark ${ }^{8}$ et la Suède ${ }^{9}$. L'Islande et les îles de la mer du Nord font aussi partie, dans les études médiévales, de la Scandinavie, en raison de leur passage sous la tutelle politique de la Norvège. Il est aussi convenu d'admettre que la culture intellectuelle scandinave au Moyen Âge s'est établie et développée sous l'influence de l' " Europe », en entendant le plus souvent par cette dernière, explicitement ou implicitement, la France, l'Allemagne, l'Angleterre, et peut-être encore l'Italie du Nord. Moins fréquemment, cette influence " européenne " fait place à la Russie, à Byzance, à la Sicile, à l'Irlande, à la péninsule Ibérique, au royaume de Naples ou à la Bohême ${ }^{10}$. L'étude de la culture intellectuelle dans la Scandinavie médiévale s'étend donc toujours à celle de l'Europe, dont elle met en question la définition même ${ }^{11}$. En outre, les tendances récentes des études médiévales vont dans le sens d'une perspective globale ou globalisante ; ainsi des recherches parallèles 
ou comparatives sont-elles menées sur l'Europe, $l^{\prime}$ Asie et l'Afrique "médiévales ${ }^{12}$. Bien que cet article, limité spatialement, s'attache principalement à la Norvège et à l'Islande médiévales ${ }^{13}$, il pourrait avoir, virtuellement, un cadre plus large. Ce dernier point, quoique latent, n'en est pas moins essentiel, et la Norvège comme l'Islande y sont considérées comme des parts actives et dynamiques de l'ensemble européen médiéval. L'histoire de la culture intellectuelle en Norvège et en Islande ne se borne pas à celle de l'adoption de modèles étrangers ou d'impulsions d'une périphérie lointaine ; elle fait preuve d'originalité tant dans la réflexion que dans l'invention d'une tradition, puisant son inspiration dans des sources locales comme extérieures.

\section{Textualité, matérialité et visualité de la culture intellectuelle}

Comme il a été dit plus haut, l'étude de la culture intellectuelle s'appuie traditionnellement sur celle des textes et des documents. La variété des dénominations médiévales de l'intellectuel, tout comme les tendances récentes des études médiévales et de l'analyse des rapports de pouvoir dans la culture (cultural studies - études culturelles) en général, développées par le nouvel historicisme, la philologie matérielle et le matérialisme culturel, plaident pour l'intégration à l'étude de la culture intellectuelle d'une plus grande variété de sources, comprenant les textes mais s'ouvrant aux matérialités. Dans la Norvège et l'Islande médiévales, les sources d'appréhension de la culture intellectuelle incluent des inscriptions latines comme runiques, des manuscrits ressortissant à différents genres textuels, parfois enluminés, des documents, des diplômes, voire des sceaux, des églises de pierre ou de bois, des châteaux et des monastères, ainsi que les peintures et les sculptures qui en ornent l'intérieur. L'accent s'est porté, de plus en plus, sur les liens entre la textualité, la matérialité et la visualité de nombre de ces sources, pertinentes dès lors qu'il s'agit d'analyser les idées et les idéologies qui en constituent l'arrière-plan.

L'épigraphie et les études runiques témoignent de ces nouvelles exigences : les chercheurs ont accordé une attention particulière aux conséquences des liens entre textualité, matérialité et visualité pour notre compréhension de la culture intellectuelle ${ }^{14}$; ils se sont penchés sur les différentes façons d'apprendre les runes ${ }^{15}$ ainsi que sur la coexistence et les écarts entre traditions latine et runique dans les mêmes environnements intellectuels ${ }^{16}$. La pierre runique de Kuli (fig. 1), la source la plus ancienne mentionnant par écrit la Norvège (Norge), considérée comme l'acte de baptême du pays, offre un parfait exemple de l'interaction complexe entre textualité et matérialité de l'inscription. On y lit : " Pórir ok Hallvarðr reistu stein penna ept Ulfljót [?] Tolf vetr hafði kristindómr verit [um rétt ?] í Nóregi [...] " ( "Tore et Halvard ont élevé cette pierre après Ulv [...] Douze hivers ont passé durant lesquels le christianisme [a rendu meilleure] la Norvège »). La visualité de la croix gravée renforce la textualité de la pierre, et c'est ensemble que ces deux vecteurs lui confèrent sa fonction de communication dans le paysage matériel, culturel et politique ${ }^{17}$. L'usage des runes était répandu, sur des bâtons (ou tablettes) runiques dans la communication quotidienne, mais aussi dans les contextes solennels des églises et des cathédrales, chez les prêtres, peut-être dans des rituels de prière pour les âmes des congrégations ${ }^{18}$.

L'apport de la nouvelle philologie a permis de reconsidérer, ces dernières années, la culture intellectuelle, en basculant le point focal, de l'auteur et de l'original textuel aux compétences, à la formation et aux intentions du scripteur, au manuscrit lui-même, et en particulier au contexte historique de sa rédaction (plutôt qu'à celui du texte original $)^{19}$. Dans sa toute récente thèse de doctorat, Katharina Heinz étudie le détail 

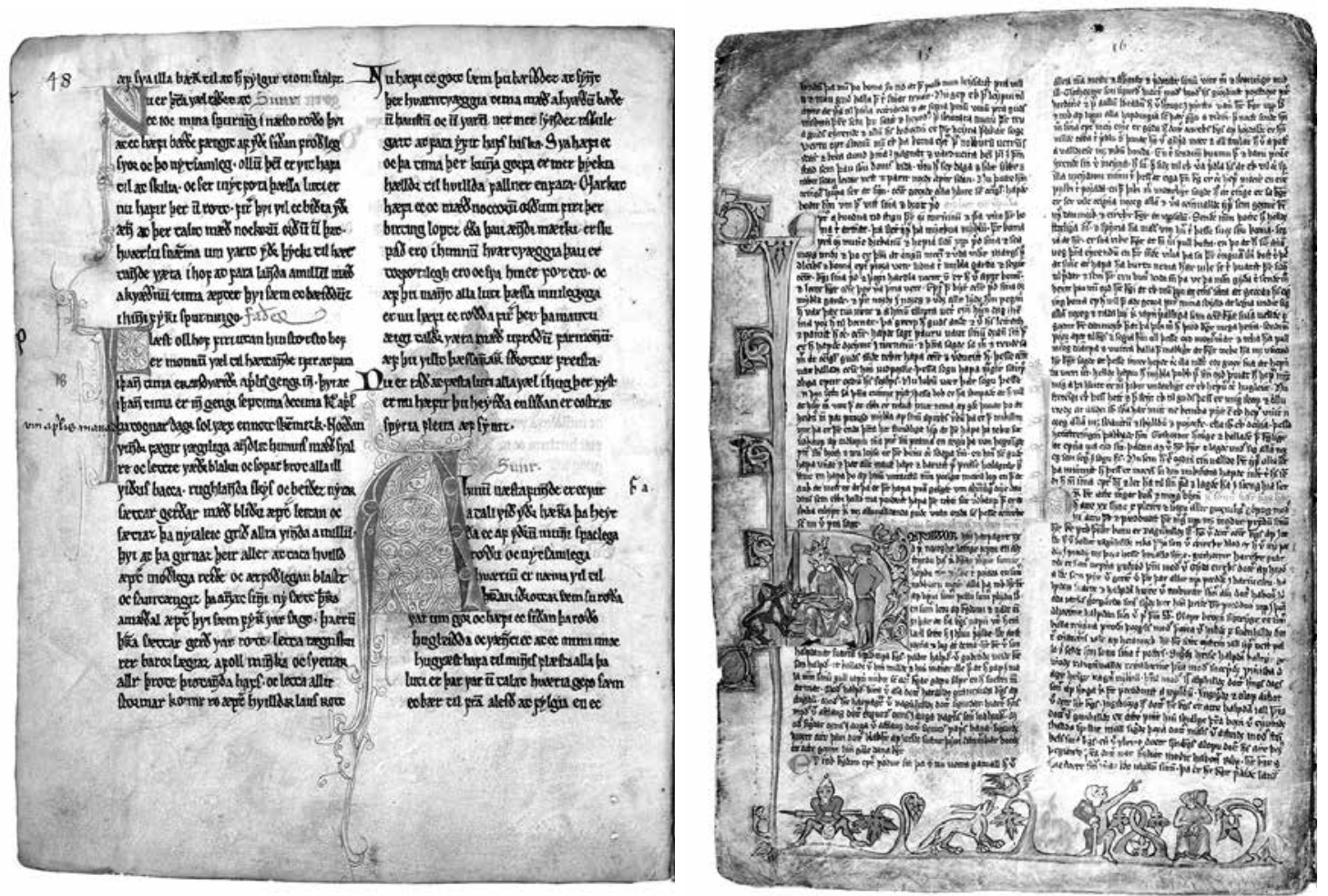

2. Le Miroir du roi, vers 1275, Copenhague, Bergen, Institut Árni Magnússon, AM243 b fol. $24 v^{\circ}$.

3. Flateyarbók, Islande, 1387-1394, Reykjavik, Institut Árni Magnússon, GKS 1005 , fol. $5 v^{\circ}$. du principal manuscrit en vieux norrois que nous ayons conservé, le Miroir du roi (fig. 2) et discute les stratégies rhétoriques classiques et pan-européennes que traduisent conjointement sa textualité et sa matérialité, ainsi que l'usage qui en est fait, directement lié à l'intention pédagogique servie par l'objet luimême ${ }^{20}$. L'anthologie The Power of the Book. Medial Approaches to Medieval Nordic Legal Manuscripts, dirigée

par Lena Rohrbach ${ }^{21}$, offre un autre exemple de ce renouveau méthodologique à l'aune des concepts de matérialité, de médialité et de textualité, et des liens entre signe et son. Les auteurs, philologues, historiens, historiens de l'art et du droit, considèrent les modes d'inscription de ces textes de loi provenant de Norvège, d'Islande, de Suède et du Danemark dans les traditions intellectuelles européennes.

Dans l'étude des idées et des idéologies corrélatives aux enluminures des manuscrits médiévaux, la méthodologie s'inspire beaucoup du tournant matériel pris par la philologie. Ainsi Lena Liepe étudie-t-elle les enluminures de livres manuscrits islandais, dont le très riche Flateyarbók (fig. 3) et s'intéresse à l'organisation de la production d'ouvrages en fonction de $l^{\prime}$ environnement intellectuel ${ }^{22}$. Une autre étude récente, consacrée aux manuscrits enluminés produits au XIV siècle par le monastère bénédictin de Pingeyrar, montre clairement comment collaboraient scribes et artistes. En résultait une abondance d'ouvrages de différents genres, des livres liturgiques, des paraphrases en vieux norrois du texte biblique, les Stjórn, des vies de saints, des livres de lois et des fictions autochtones ou traduites. Ces ouvrages étaient peut-être destinés à l'exportation vers la Norvège, à l'appui donc de liens assez étroits qui auraient uni les élites politiques et intellectuelles norvégiennes et les bénédictins du Nord de l'Islande ${ }^{23}$. Outre l'usage probable de modèles venus d'Europe continentale pour les enluminures ${ }^{24}$, 
un recueil de modèles islandais, un teiknibókin, a récemment retenu l'attention à l'occasion notamment d'une édition fac-similée ${ }^{25}$. Ce manuscrit a certainement servi de modèle aux peintres enlumineurs islandais pour la composition aussi bien des initiales que des enluminures à proprement parler.

L'étude des sceaux, dans la mesure où ils authentifiaient la matérialité comme le contenu de lettres écrites par des membres de la famille royale ${ }^{26}$, par des abbés, des prieurs ou des abbesses ${ }^{27}$, est également d'un grand apport dans la compréhension des jeux entre textualité et matérialité. Leur iconographie est aussi interprétée au regard des idées et des idéologies, mais aussi de l'histoire de l'architecture des institutions intellectuelles elles-mêmes ${ }^{28}$.

Lorsque l'on aborde la matérialité médiévale, le lien avec le sacré, voire les reliques, est particulièrement important, comme l'a montré le travail séminal de Caroline Bynum ${ }^{29}$. L'intérieur des églises médiévales, leurs peintures, leurs sculptures livrent des clés d'interprétation de la culture intellectuelle et religieuse de la Norvège et de l'Islande médiévales, non seulement dans les singularités de leurs styles, à l'exemple de l'église en bois debout d'Urnes (fig. 4), de leur iconographie et de leur structure, mais aussi dans leur matérialité propre ${ }^{30}$. Ainsi la visualité de l'expression polychrome dans la sculpture médiévale est-elle aujourd'hui considérée dans sa cohérence avec les enseignements de la théologie chrétienne sur l'éveil spirituel, imagé par un chemin où le regard intérieur est conduit de l'obscurité à la lumière (fig. 5 l $^{31}$. La croix de l'église médiévale de Borre en Norvège, dite "Sainte Croix ", était conçue comme une manifestation matérielle du pouvoir divin et, à ce titre, pleurait, saignait, exerçait sur le sort des croyants une influence concrète. Dans sa thèse de doctorat, Kaja Merte Haug Hagen s'attache à comprendre comment la fonction de ces saints objets changea avec la diffusion de la Réforme en Norvège, apportant un regard neuf sur la façon dont était envisagée la présence divine dans la matière avant et après la Réforme ${ }^{32}$.
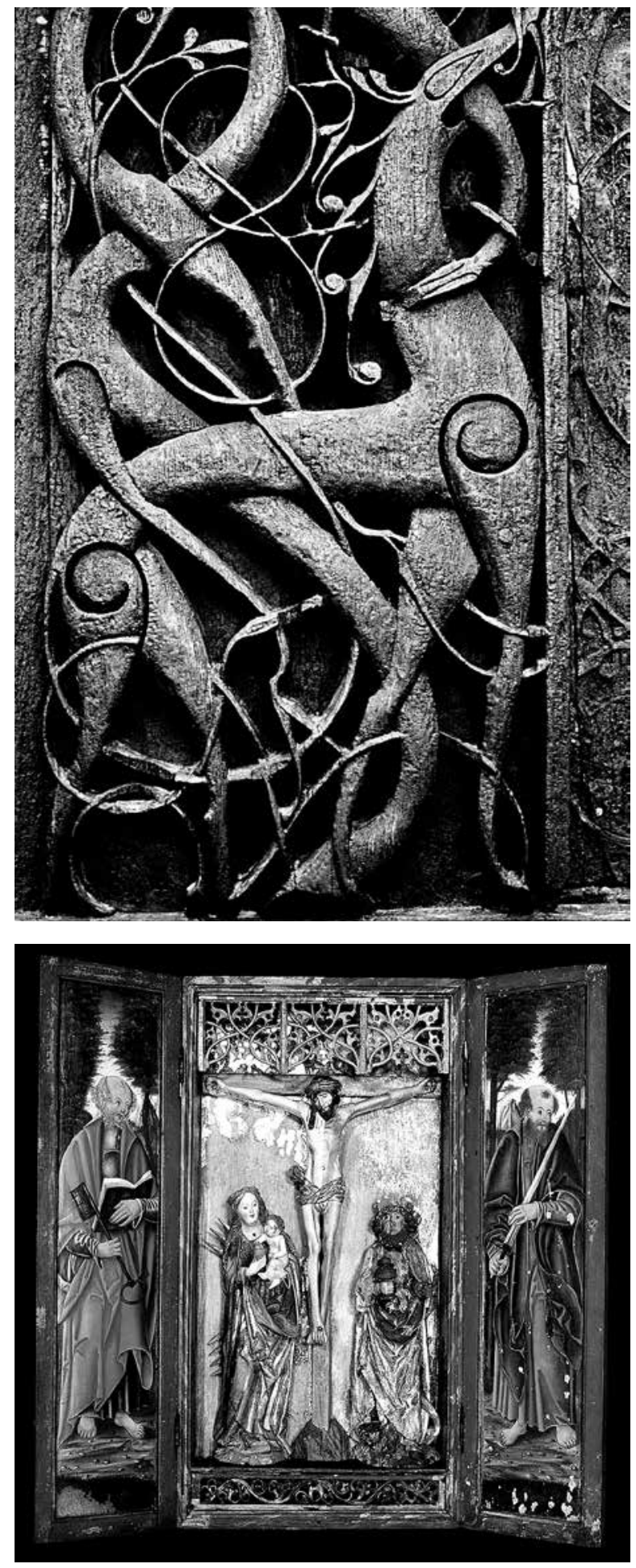

4. Scupltures de l'église en bois debout d'Urnes (Norvège, comté de Sogn og Fjordane), vers 1140.

5. Retable sculpté polychrome, église d'Hopenes (Norvège, comté de Møre og Romsdal), Oslo, Musée d'histoire culturelle. 
L'importance des liens entre textualité, matérialité et visualité pour la compréhension de la culture intellectuelle est parfois mesurée à l'aune du contexte ou de l'environnement plus vaste d'un centre intellectuel considéré dans sa globalité. Les récentes recherches menées autour de l'activité du poète, historien et grand érudit des lettres islandaises, Snorri Sturluson (1179-1241) à Reykholt (alors nommée Reykjaholt), qui ont récemment mobilisé une nombreuse équipe pluridisciplinaire pour tenter de définir les conditions matérielles et locales ayant vu s'épanouir la culture intellectuelle islandaise au XIII ${ }^{\mathrm{e}}$ siècle, en offrent un exemple éloquent ${ }^{33}$. De même, les chercheurs se sont penchés sur le milieu politique, culturel et intellectuel de Niðarós (l'actuelle Trondheim), siège archiépiscopal jusqu'à la Réforme, et sur ses relations avec l'Église en se fondant sur des sources textuelles et matérielles ${ }^{34}$. Un autre projet de recherche interdisciplinaire développe le concept de " Jerusalem Code " et étudie les idées et les représentations de la Jérusalem terrestre et céleste dans les sources textuelles comme dans celles de l'histoire des arts, du Moyen Âge au début du XX $x^{\mathrm{e}}$ siècle ${ }^{35}$. Enfin, un grand projet, porté par l'université de Zurich $^{36}$, se consacre à l'histoire de la communication et de ses supports, en étudiant la médialité et la matérialité de l'expression culturelle dans la Scandinavie médiévale, à partir des textes, des manuscrits et des objets.

\section{Penser en termes de continuités}

Un autre courant méthodologique récent de la recherche sur la culture intellectuelle consiste à remettre en cause la pertinence des dichotomies et à privilégier les continuités. Cette approche a le mérite de permettre d'analyser les interdépendances entre les patrimoines chrétien et préchrétien, entre les sources extérieures et locales, l'oralité et la scripturalité, l'usage de la langue vernaculaire et celui de la langue latine.

\section{Christianisation}

Le christianisme constitue l'un des principaux éléments de légitimation de la culture intellectuelle de la Norvège et de l'Islande médiévales comme culture européenne. S'il réunit le lointain monde nordique au centre religieux, encore a-t-il des structures et des caractéristiques locales. Ainsi en Islande la réunion de l'ordre laïc et de l'ordre clérical marqua-t-elle profondément le développement d'une culture intellectuelle singulière. L'Islande est connue pour son Église de chefferie, ou goðakirkja, ce qui signifie qu'en pratique le chef d'une exploitation et d'une habitation agricole pouvait exercer la fonction de prêtre. L'Islande, durant la période de l'État libre, qui va de la création de l'institution judiciaire de l'Alpingi, en 930, à sa soumission au souverain de Norvège, en 1262, n'ayant pas connu de pouvoir politique et exécutif centralisé, le christianisme n'avait peut-être pas d'autre façon de s'y établir que d'en adopter les structures existantes, en l'occurrence de recruter les élites religieuses parmi les chefs des fermes qui en constituaient les unités démographiques et économiques, déjà intégrés au clergé durant l'ère préchrétienne. Cette réunion de la fonction et de la compétence eut certainement une grande influence sur la culture intellectuelle produite en Islande ${ }^{37}$.

D’une façon similaire, la transmission des idées préchrétiennes (et non seulement des structures sociales préchrétiennes) dans la littérature médiévale et dans la culture textuelle est un sujet largement débattu. La principale évolution dans ce domaine concerne les mythes préchrétiens de la littérature médiévale et leur fidélité à la mythologie préchrétienne, or ces mythes furent écrits par des auteurs et des scribes chrétiens, dont les cadres de pensée durent certainement influencer les intentions et la rédaction. Progressivement, 


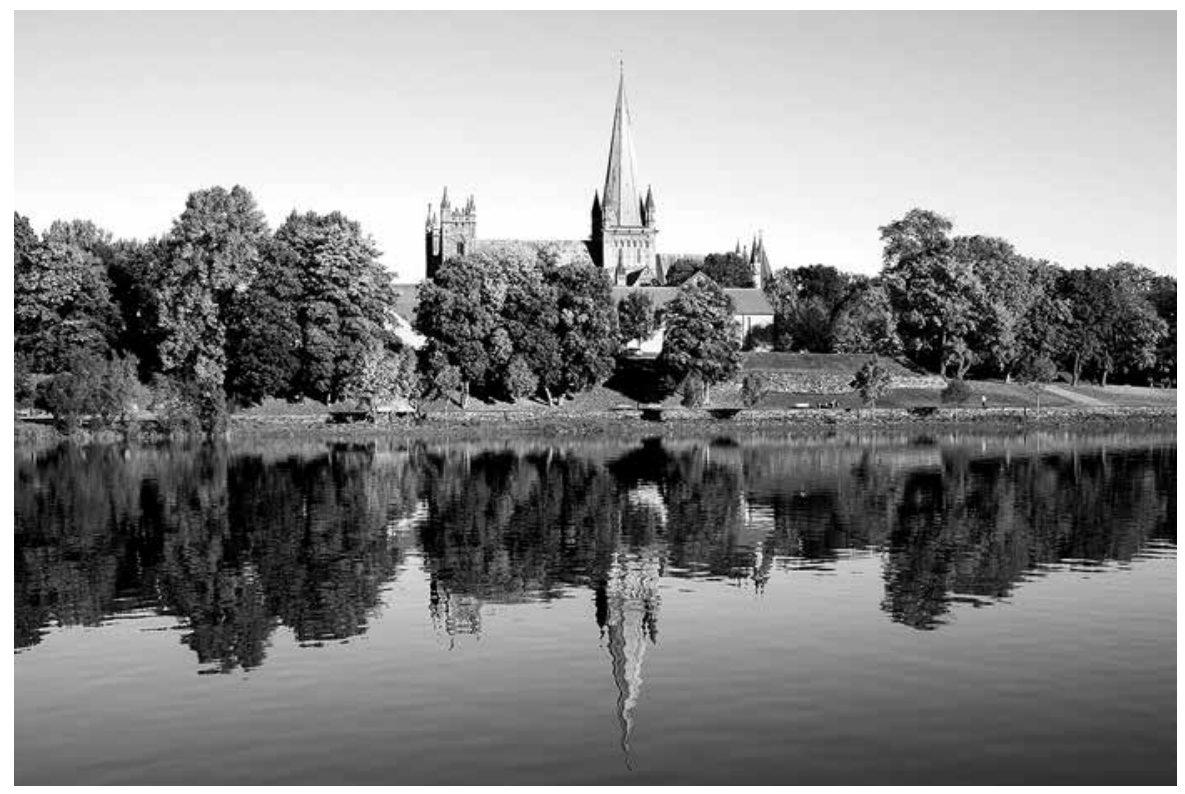

de nombreux chercheurs ont admis la "plasticité " de 6. Cathédrale de Niðarós, Trondheim. nombreuses métaphores et figures, avec leurs sens, tant dans les cadres préchrétiens que chrétiens ${ }^{38}$.

La fondation de l'Église et son développement fournissent les limites chronologiques traditionnelles du Moyen Âge en Norvège et en Islande, qui commence avec la christianisation dans l'un et l'autre contexte, aux alentours de l'an mil (après l'âge viking, des alentours de l'an 800 à l'an mil) et se clôt avec la Réforme, en 1537. L'archevêché de Niðarós, fondé en 1152 , comprenait l'Islande. Après 1264, la Norvège et l'Islande formèrent une même unité politique, avec des particularismes administratifs locaux ${ }^{39}$. L'Union de Kalmar (13971521), avec le Danemark et la Suède, voit les deux pays, qui ne constituent qu'un seul des trois royaumes, rejetés dans la périphérie politique ${ }^{40}$. La Réforme de 1537 bouleverse les structures des deux contextes. Si l'histoire ne s'est pas faite et ne se fait pas du jour au lendemain, ces dates ont le mérite de fournir des repères utiles. Considérer l'arrivée puis la diffusion et le développement du christianisme dans une continuité temporelle et idéologique de long terme, qui englobe ces repères chronologiques, permet de mettre au jour de nouveaux caractères de la culture intellectuelle en Norvège et en Islande.

\section{Européanisation}

Comme nous l'avons vu à grands traits, la culture intellectuelle, c'est-à-dire les idées et les idéologies, n'a pas de limites géographiques clairement définies. Ce qui la compose voyage, évolue, se traduit, dans différents contextes et différentes langues, emprunte différents vecteurs. La représentation courante d'un Nord périphérique, et par conséquent réceptacle des idées et des élans venus du centre, a fait l'objet de nombreux débats. La transmission des idées était beaucoup plus dynamique et complexe que ne le laisserait penser cette conception univoque, et les intellectuels eurent un rôle actif tant dans l'adaptation des impulsions européennes au contexte cible ${ }^{41}$ que dans la formation de l'Europe médiévale chrétienne en général ${ }^{42}$. Ce processus d'adaptation dynamique a été abondamment exploré pour ce qui concerne l'usage de modèles européens 


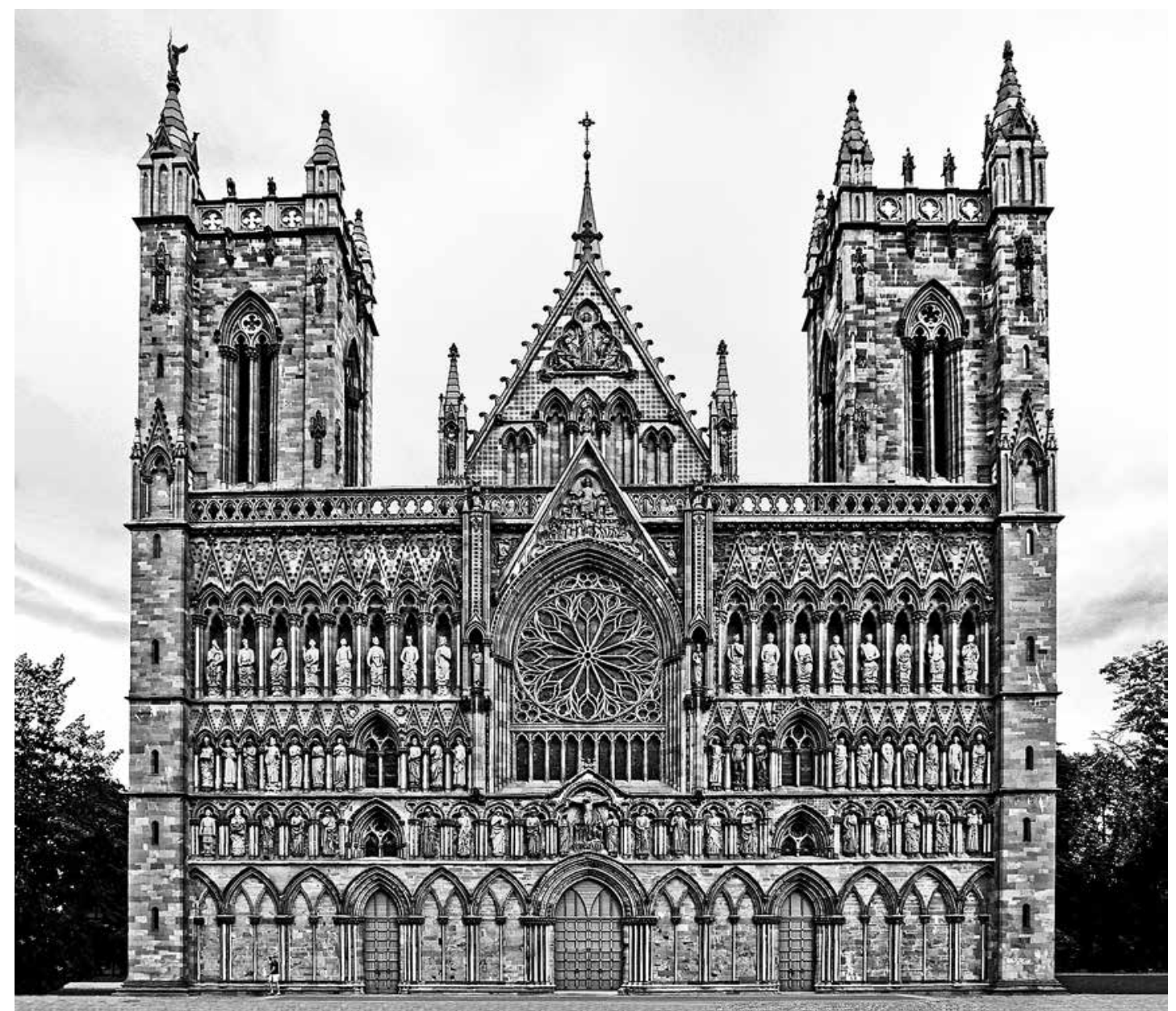

7. Façade occidentale de la cathédrale de Niðarós, Trondheim. dans la composition des textes ${ }^{43}$ et dans les réalisations des arts $^{44}$ et de l'architecture ${ }^{45}$. La cathédrale de Niðarós (fig. 6 et 7), qui présente des traits gothiques pan-européens mais fut également construite pour répondre aux besoins d'une communauté locale et à l'instauration du culte voué au saint national, Olav, en fournit un exemple particulièrement riche ${ }^{46}$.

L'ouverture des frontières spatiales et temporelles conduit à nuancer des vérités « établies » dans le monde savant, comme par exemple l' « absence » de culture intellectuelle après la Peste noire, notamment en Norvège. Jonathan Adams, entre autres, a montré l'influence du monastère de Vadstena et de l'ordre de Brigittines dans les dynamiques de création, en Norvège, à la fin du XIV siècle, une période qui symbolisait auparavant le déclin culturel ${ }^{47}$.

\section{Scripturalisation, oralité et performativité}

Outre leurs représentations écrites et matérielles, les idées et les idéologies étaient aussi communiquées oralement, et l'association de l'oralité, de la scripturalité (literacy) et de la performativité / performance de la culture intellectuelle attire de plus en plus l'intérêt des chercheurs. Avant l'introduction du christianisme et de la culture du livre, la Norvège 
et l'Islande eurent une riche tradition orale, poétique et narrative, sans compter la littérature runique, évoquée plus haut. La culture orale ne disparut pas avec l'introduction de la culture du livre. Les marques respectives d'oralité et de scripturalité dans la culture intellectuelle en Norvège et en Islande ont fait l'objet de nombreux débats, inévitablement liés à des questions d'historicitét ${ }^{4}$. Le courant dominant consiste aujourd'hui à insister sur la continuité entre oralité et scripturalité dans les différents genres littéraires - sagas ${ }^{49}$, poésie eddique ${ }^{50}$, et autres ${ }^{51}$.

Même si les sources médiévales préservées jusqu'à nos jours sont exclusivement écrites et matérielles, des concepts comme la musicalité52 , la vocalité, l'auditivité (intentionnalité de lecture à voix haute et par conséquent d'audition dans un texte ${ }^{53}$ ) et performativitée ${ }^{54}$ prennent une part de plus en plus importante dans les débats, qui mettent l'accent sur les modes performatifs de communication et de participation dans la culture intellectuelle. La performance agissante des rituels religieux est également étudiée dans la prise en compte de l'architecture considérée comme espace rituel religieux ${ }^{55}$, de la transformation des églises en bois debout et du remploi de certains de leurs éléments ${ }^{56}$ (fig. 8), voire des monnaies trouvées sous les planchers de ces églises ${ }^{57}$.

\section{Vernacularisation et latinisation}

La langue constitue bien évidemment une variable d'importance dans l'analyse de la culture intellectuelle. Selon une hypothèse répandue, la tradition littéraire en norrois différait dans une certaine mesure des autres contextes culturels de l'Europe médiévale en raison de la vigueur de la langue vernaculaire et de la tradition poétique $\mathrm{s}^{\prime} \mathrm{y}$ rattachant (poésies scaldique et eddique) avant l'appropriation de la tradition latine. Néanmoins, la tradition littéraire en vieux norrois comprend nombre des principaux genres pan-européens comme la chronique royale, l'hagiographie, le " roman " et le récit de croisade. Ces traits communs ne sont pas les fruits d'emprunts passifs mais d'une appropriation et d'une adaptation actives à un nouveau contexte socio-culturel cible, comme le montrent les résultats récents des études culturelles en général et notamment des travaux consacrés à la traduction ${ }^{58}$.

En Islande et en Norvège, la langue vernaculaire jouait déjà, avant l'introduction de la culture latine du livre, un rôle important, littéraire et poétique mais aussi juridique. C'est dans cette langue qu'on enseignait et qu'on apprenait les lois, par les récits notamment de cas célèbres, par l'histoire et la formation religieuse ${ }^{59}$. À la différence de leurs homologues danois et suédois, les intellectuels norvégiens et islandais embrassèrent et reproduisirent, en y apportant leurs innovations, la culture latine mais ne produisirent guère d'œuvres originales en latin. Si la culture textuelle latine exista bel et bien, les érudits eurent tendance à lui donner moins d'importance qu'aux genres nordiques canoniques. En outre, les manuscrits latins furent dépréciés lors de la Réforme, quoique beaucoup soient encore

8. Église en bois debout de Borgund, vers 1150-1200, Lærdalen, comté de Sogn og Fjordane, Norvège.

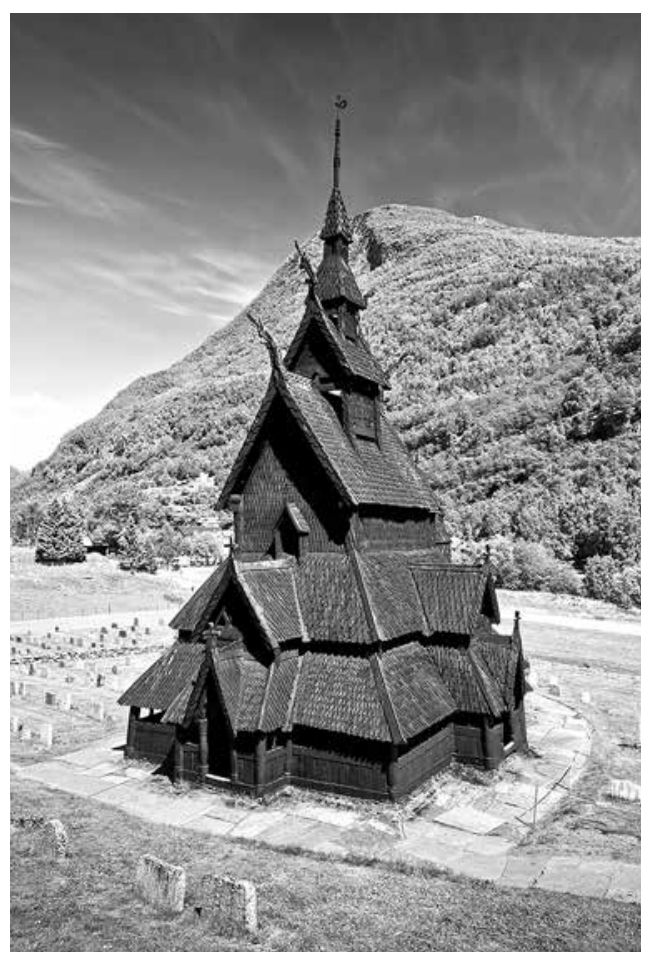


disponibles et doivent être pris en compte dans le débat ${ }^{60}$. L'influence de la langue latine et des textes en latin sur le développement de la culture littéraire vernaculaire en Norvège et en Islande est progressivement admise par un nombre croissant de chercheurs ${ }^{61}$. De nombreux genres et textes latins furent traduits en vieux norrois, et il n'est pas rare que la culture textuelle autochtone en vieux norrois ait elle-même repris certains postulats et modèles latins ${ }^{62}$. Ces derniers n'étaient pas copiés servilement mais utilisés de façon créative, engendrant des œuvres originales en langue vernaculaire ${ }^{63}$.

Le latin ne fut pas la seule influence linguistique et culturelle qu'ait connue le Nord. Des traductions du français et de l'allemand furent réalisées à la demande de souverains norvégiens, tels les rois Hakon IV (1217-1263) et Magnus VI (1263-1280) ou la reine Euphemia (1270-1319) ${ }^{64}$. Outre les traductions, nous disposons de fragments de manuscrits français et allemands indiquant qu'une partie au moins du lectorat norvégien maîtrisait ces deux langues ${ }^{65}$. Les traductions des romans européens inspirèrent par ailleurs la composition de romans autochtones et une riche tradition islandaise de ballades ${ }^{66}$.

\section{Les intellectuels : les hommes et les femmes, les enfants et les autres}

Une autre tendance dans l'appréhension, aujourd'hui, de la culture intellectuelle nordique, nourrie par les travaux européens, consiste à considérer une plus grande variété de classes sociales comme agents potentiels de la culture intellectuelle, à savoir ses créateurs, ses interprètes et ses acteurs à différents niveaux ${ }^{67}$. La représentation des femmes dans la littérature, leurs fonctions et leurs voix ont reçu de plus en plus d'attention, que ce soit à partir de l'étude des genres autochtones ou traduits ${ }^{68}$. Leur rôle socio-politique, celui, notamment, de celles qui ont occupé des positions de pouvoir, a encore été identifié comme un marqueur du développement de la culture intellectuelle ${ }^{69}$. L'action et le rôle des enfants reçoivent aussi, depuis peu, une attention plus soutenue, car ces derniers, s'ils ne furent peut-être pas des producteurs directs de culture intellectuelle, en furent certainement des consommateurs, négligés auparavant ${ }^{70}$. Enfin les " autres ", du point de vue social ou religieux, les juifs, les musulmans, les Samis, ont fait leur entrée dans le débat, à partir de leurs représentations dans les textes ${ }^{71}$ comme dans l'art ${ }^{72}$. L'idée d'une plus grande variété d'acteurs sociaux ayant fait valoir leurs droits et leurs voix est aussi corroborée par les sources juridiques ${ }^{73}$.

\section{Les intellectuels et les processus d'idéation : mémoire, émotions et cognition}

Un dernier courant du débat récent doit être abordé ici : l'intérêt croissant porté à la culture intellectuelle comme processus. Cette approche implique une meilleure connaissance de la perception médiévale des facultés cognitives ainsi que de la mémoire et des émotions. La question de la mémoire a évidemment gagné en visibilité dans les recherches sur le vieux norrois $^{74}$, suite aux travaux décisifs de Mary Carruthers et de Jan Assmann. S'affirment désormais dans ce domaine deux grandes idées : la mémoire doit être considérée comme un processus créatif, sélectif et dynamique (non comme un contenant statique empli de faits "vrais " et immuables) ; elle est tout à la fois individuelle, sociale et culturelle. Elle a pour fonction de créer une version efficace du passé historique et de légitimer, collectivement et individuellement, toute nouvelle situation socio-culturelle ou politique. Le très récent Handbook of Pre-Modern Nordic Memory Studies, sous la direction de Jürg 
Glauser, Pernille Hermann et Stephen A. Mitchell ${ }^{75}$ réunit des articles provenant des traditions et des disciplines les plus diverses et de nombreuses études de cas alimentées à différentes sources textuelles, matérielles et artistiques.

Si les émotions ont pu être tenues pour étrangères à la culture intellectuelle, à la lumière des développements actuels des sciences cognitives, elles ont toute leur place dans le processus de connaissance, au même titre que le raisonnement et la rationalité. En outre, selon les principes de la rhétorique médiévale, la persuasion résultait aussi bien d'un effort rationnel d'argumentation que d'une aptitude à transmettre un message émotionnel. Du point de vue de la rhétorique, les émotions étaient donc placées sur un plan parallèle à celui de la raison. Leur représentation littéraire (qu'il faut bien distinguer de leur réalité) apparaît ainsi comme une pièce du puzzle dans l'examen des processus et des facultés intellectuelles. Cette matière, comme celle de la mémoire, reçoit dans $l^{\prime}$ histoire culturelle en général ${ }^{76}$, tout comme dans les études médiévales ${ }^{77}$, une grande attention. Elle est étudiée en profondeur pour le vieux norrois dans le dernier ouvrage de Sif Rikhardtsdottir, Emotion in Old Norse Littérature. Translation, Voices, Contexts, à partir de cinq textes, genres et contextes différents, appartenant à la littérature traduite aussi bien qu'autochtone $^{78}$. Le point principal est encore une fois celui de l'épanouissement de la culture intellectuelle scandinave en relation étroite avec les représentations européennes des processus cognitifs et émotionnels.

La définition de la culture intellectuelle comme un processus cognitif dynamique correspond aussi à la perspective centrale du livre dirigé par l'auteure de ces lignes, Intellectual Culture in Medieval Scandinavia ${ }^{79}$, dont les articles interrogent différents types de sources - littérature, récits historiques, art, architecture - en tant que produits des processus intellectuels de leurs agents, que ceux-ci soient auteurs ou scribes, mécènes, maîtres d'ouvrage ou usagers. En étudiant l'expression culturelle d'un point de vue cognitif, on souligne le rôle de ses producteurs, des motifs, des émotions, des corps qui la sous-tendent et de l'environnement où elle s'inscrit. La culture intellectuelle est donc toujours le produit d'un contexte culturel historique, mais aussi de l'activité d'humains qui ont les capacités cognitives de vouloir ou de désirer l'évolution ou la conservation de la culture à laquelle ils appartiennent. Les individualités créatrices les plus connues ont toujours reçu beaucoup d'attention ${ }^{80}$, mais ce livre montre - et c'est l'idée même sur laquelle il est construit - que derrière chaque expression culturelle, se trouvent un individu et une volonté (ou agency) intellectuelle, même lorsque cette volonté est anonyme. Une réalité souvent oubliée ou négligée lorsqu'il s'agit du vieux norrois et de sa culture, où l'anonymat (à l'exception de quelques auteurs connus et de nombreux poètes scaldiques) est beaucoup plus courant que dans le reste de l'Europe médiévale, qui a plus souvent enregistré les noms de ses grands penseurs ou de ses écrivains.

\section{Qu'est-ce que la culture intellectuelle ?}

Cet article avait pour objectif de recenser les principaux points de départ théoriques et méthodologiques de la recherche sur la culture intellectuelle (définie comme constituée d'idées et d'idéologies), à partir des sources matérielles et textuelles provenant de la Norvège et de l'Islande médiévales. Nous avons vu que cette culture intellectuelle était de plus en plus comprise comme inhérente aux sources textuelles et matérielles, tout comme aux performances / actions orales et rituelles. La culture intellectuelle - c'est-àdire les idées et les idéologies - n'est pas contrainte dans des limites géographiques; elle voyage et se transforme avec ses agents individuels et collectifs, à savoir ses créateurs, ses interprètes, ses participants et ses acteurs / actants. La pluralité des contextes sociaux 
dont sont issus ses agents est de plus en plus reconnue. Si importantes que soient les communautés et les institutions intellectuelles, les intellectuels sont de plus en plus considérés comme des individus, avec leurs facultés cognitives complexes, leur raison, leur mémoire, leurs émotions. La culture intellectuelle de la Norvège et de l'Islande médiévales peut être comprise comme une adaptation de la culture intellectuelle européenne, mais elle eut aussi ses traits particuliers et singuliers, conséquences de son histoire, de l'usage du vieux norrois comme langue vernaculaire, de l'existence d'un système d'écriture distinct (les runes) lorsque se répandit la maîtrise du latin, de la présence, lorsque commencèrent d'être traduits les genres chrétiens, d'une tradition poétique locale vivante et singulière (la poésie scaldique et eddique), de dynamiques unissant les mythes chrétiens et nordiques, où les mêmes métaphores pouvaient être convoquées, mais avec des significations différentes. Les futures recherches doivent relever le défi d'une équilibration des cultures intellectuelles autour de caractères qui tiennent à la fois du local et du global, d'un contexte historique précis et d'un processus de long terme, inhérents à divers modes de matérialité et fruits singuliers d'expressions spécifiques, reflets de préoccupations individuelles et de besoins collectifs.

Cette contribution a été traduite de l'anglais par François Boisivon. 


\section{Stefka G. Eriksen}

Stefka G. Eriksen est professeure chargée de recherche à l'Institut de recherches sur le patrimoine culturel d'Oslo. Elle est l'auteure de Writing and Reading in Medieval Manuscript Culture (2014) et a dirigé l'édition de Intellectual Culture of Medieval Scandinavia (2016). Ses champs d'intérêt et de publication s'étendent aux traductions en vieux norrois, aux attitudes envers le savoir et la cognition. Elle est directrice scientifique du projet The Self in Social Spaces (2016-2020), financé par le Conseil de la recherche norvégien.

\section{NOTES}

1. LE GOFF, (1957) 1993.

2. COPELAND, 2005.

3. WEI, 2014.

4. En abordant la culture intellectuelle dans des termes aussi généraux, on ne peut manquer d'évoquer le travail de Mary Carruthers sur la mémoire et le souvenir, voir CARRUTHERS, 1994 ; sur la pensée, voir LIBERA, 1991 ; et parmi d'autres publications sur les universités médiévales, les écoles, les institutions monastiques mais aussi les structures politiques, voir, par exemple, JAEGER, (1994) 2013.

5. On s'en remettra pour cela à d'autres publications : voir HARĐARSON, 2016. L'article insiste sur la « nature irisée » de la culture intellectuelle, dans la mesure où elle comprend l'écriture, la récitation et la communication orales, l'instruction et la maîtrise des termes du débat juridique (p. 36). Sur les étudiants norvégiens à l'étranger, voir BAGGE, 1976 et 1984.

6. Voir ci-dessous.

7. D'autres sujets auraient pu être abordés, par exemple celui de la périodisation (le long Moyen Âge), mais ils intéressent plutôt une analyse générale de la culture intellectuelle.

8. Sur la culture intellectuelle du Danemark médiéval, notamment sur Saxo Grammaticus (1160-1220), Anders Sunesen (1167-1228) et Martin de Dacie (1220-1304) voir les travaux de Karsten Friis-Jensen et les articles de C. Stephen Jaeger, Thomas Foester et Jenny Benham dans MÜNSTER-SWENDSEN, HEEBØLL-HOLM, SØNNESYN, 2016. Pour une analyse de la fonction intellectuelle des ornements dans les églises danoises, voir BONDE, 2019.

9. Sur la culture intellectuelle suédoise, voir par exemple FERM, KIHLMAN, 2011 ; sur Vadstena, voir GEJROT, RISBERG et ÅKESTAM, 2010. Sur la postérité et l'œuvre de Brigitte en Suède et en Europe, voir les travaux menés par Roger Andersson (" Heliga Birgitta på fornsvenska »), Unn Falkeid (" The Legacy of Birgitta of Sweden. Women, Politics and Reform on Renaissance Italy »), Laura Saetveits Miles (" The English Cult of St. Birgitta of Sweden: Reception and Influence, 1380-1530»). Voir aussi OEN, SAHLIN, 2018. Sur la culture intellectuelle dans ses rapports à l'art et à l'architecture, voir NILSÉN, 2014.
10. L'étude de la littérature médiévale sur un spectre aussi large est l'un des principaux objectifs des chercheurs du Centre pour la littérature médiévale $(\mathrm{CML})$, dirigé par Lars Boje Mortensen et Elizabeth M. Tyler (http://cml.sdu.dk). Voir la nouvelle revue Interfaces: $A$ Journal of Medieval European Literature (https://riviste. unimi.it/interfaces/index).

11. Voir, par exemple, BARTLETT, 1993.

12. Voir, par exemple, Defining the Global Middle Ages (https://www.history.ox.ac.uk/defining-global-middle-ages) et Global Middle Ages (en ligne, URL : http:// globalmiddleages.org).

13. Cette approche a été critiquée par des chercheurs comme Lars Boje Mortensen, pour qui les organismes de recherche nationaux, malgré l'intention affichée d'aborder la culture médiévale en dehors de toute visée « nationalisante ", déterminent encore notre compréhension de la situation médiévale pré-nationale ; voir Mortensen, "Review of Stefka G. Eriksen Intellectual Culture in Medieval Scandinavia, c. 1100-1350", dans Sehepunkte, no 17, 2017, p. 6 [en ligne, URL : https://www.recensio. net/rezensionen/zeitschriften/sehepunkte/17/06/intellectual-culture-in-medieval-scandinavia-c (consulté le 4 janvier 2019)].

14. ZILMER, 2010. Voir aussi BAUER, KLEIVANE et SPURKLAND, 2018.

15. NORDY, 2018.

16. Voir le projet en cours Between Runes and Manuscripts, conduit par Elise Kleivane à l'université d'Oslo (en ligne, URL : https://www.hf.uio.no/iln/english/research/ projects/between-runes-and-manuscripts/).

17. HAGLAND 1998.

18. Voir HOLMQVIST, 2018. Pour une étude similaire, à partir de sources suédoises, voir KäLLSTRÖM, 2012.

19. Pour une étude critique récente des sources matérielles, voir LÖNNROTH, 2017.

20. HEINZ, 2019.

21. ROHRBACH, 2014.

22. LIEPE, 2009, qui s'appuie sur KRISTJÁNSSON, 1996 et HERMANNSSON, 1935. Pour une étude du même ordre des enluminures produites à Helgafell, voir DRECHSLER, 2017. II y analyse les affinités intellectuelles entre Helgaffel en Islande, Norwich dans I'East Anglia britannique et les villes de Bergen et de Trondheim dans I'Ouest de la Norvège.

\section{KRISTJÁNSDÓTTIR, 2016.}

24. Une série de cartes circulaires de Jérusalem, dans trois manuscrits islandais, témoigne à cet égard d'une nette influence européenne. Ce type de cartes, connues dans des manuscrits du XII ${ }^{\text {e }}$ siècle contant les croisades, apparaissent ici dans des manuscrits à vocation encyclopédique, dans le possible objectif d'intégrer les notions européennes d'une Jérusalem terrestre et céleste au contexte intellectuel islandais du XIVe siècle.

\section{KRISTJÁNSDÓTTIR, 2013.}

26. BREGAINT, 2016.

27. HARĐARDÓTTIR, 2016.

28. HARĐARDÓTTIR, 2016. 
29. WALKER BYNUM, 2011.

30. STREETON, KOLLANDSRUD, 2014

31. KOLLANDSRUD, 2018.

32. voir le site : http://www.tf.uio.no/english/research/ phd/phdprojects/hagen-kaja-merete-haug/index.html.

33. PORLÁKSSON, SIGURĐADÓTTIR, 2012 ; SVEINBJARNARDÓTTIR, PORLÁKSSON, 2018.

34. IMSEN, 2003.

35. Objectif principal du projet Tracing the Jerusalem Code (https://www.mf.no/en/researchphd/ongoingresearch-projects/tracing-jerusalem-code), qui vient de livrer ses premiers résultats sous la direction de Kristin B. Aavitsland. Voir AAVITSLAND, BONDE, 2019.

36. Voir le site : http://www.mediality.ch/e_abstract.php.

37. HARĐARSON, 2016, p. 37-38.

38. CLUNIES ROSS, 1999 ; ERIKSEN, 2018, sous presse ; WELLENDORF, 2010.

39. Voir KARLSSON, 2000 ; PORLÁKSSON, 2005.

40. E. Haug, "Erik av Pommerns Norske Kroning ", dans Historisk Tidsskrift, n ${ }^{\circ} 74,1995$, p. 1-21.

41. Parmi les publications récentes sur le sujet, WOLF, VAN DEUSEN, 2017. Sur l'interdépendance entre les cloîtres islandais et les institutions religieuses européennes, voir BERNHARĐSSON, 2016.

42. Voir, par exemple, SALONEN, VILLADS JENSEN et JØRGENSEN, 2013. L'ouvrage, qui comprend des articles sur la Baltique et la Suède, élargit les géographies médiévales traditionnelles.

43. Voir, par exemple, les analyses du Miroir du roi, en vieux norrois, exposées dans JOHANSSON, KLEIVANE, 2018. L'ouvrage est publié dans la collection Bibliotheca Nordica, qui propose de nombreux textes témoignant de l'européanisation de la littérature en vieux norrois. Voir aussi GRøNLIE, 2017.

44. Voir, par exemple, KAUSLAND, 2016.

45. Voir par exemple l'étude consacrée à l'église ronde de I'abbaye norbertine de Saint-Olav à Tønsberg par Bjørn Bandlien : BANDLIEN, à paraître ; ou HAUGLIG, 2016.

46. EKROLL, 2003.

47. ADAMS 2016.

48. Pour une synthèse, voir SIGURĐSSON, 2005.

49. Pour une publication récente sur le sujet, voir ANDERSSON, 2012. La nature plurielle de la saga médiévale, son oralité et son historicité, son inventivité et sa scripturalité y sont examinées. Pour Andersson, le développement de la saga islandaise, tout comme les sagas royales, est clairement lié au contexte politique, marqué par les dynamiques des relations entre rois norvégiens et chefs de localités agricoles islandais.

50. Voir, par exemple, GUNNELL, LASSEN, 2013 ; CLUNIES ROSS, 2018.

51. RANKOVIC, MELVE, MUNDAL, 2010.

52. ATTINGER, 2004.

53. Pour une étude consacrée à l'histoire du livre et à l'évolution des habitudes de lecture, fondée sur la matérialité des manuscrits, voir ERIKSEN, 2014.
54. Voir BOJE MORTENSEN, LEHTONEN, BERGHOLM, 2013. L'ouvrage s'intéresse principalement aux genres et aux textes non canoniques - littérature "représentée » et performativité - d'un côté, de l'autre à la latinité et aux interactions entre le latin et la langue vernaculaire. Voir aussi GUNNELL, 2008. Sur la performativité et l'immersion émotionnelle et corporelle dans les rituels, voir ANDÅs, EKROLL, HAUG et al., 2007. Margrete Syrstad Andås travaille aussi à un projet consacré aux « images de l'entrée ", qui convoque différentes sources textuelles et matérielles pour éclairer le sens de la promesse d'entrée des âmes dans la Jérusalem céleste et des rituels qui en ouvraient éventuellement les portes, comme le baptême, la confession et la pénitence.

55. ANDÅS, EKROLL, HAUG et al., 2007.

56. Dans sa thèse de doctorat en cours de rédaction, Linn Willetts Borgen s'attache aux usages et aux remplois pour les églises en bois debout sur la période $1247-$ 1723 (https://www.hf.uio.no/iakh/personer/vit/historie/ midlertidig/linn-borgen/). En étudiant les évolutions et les continuités des techniques constructives, et parfois le remploi de certains éléments des anciennes églises, avant et après la Réforme, Borgen se donne pour but d'améliorer notre compréhension des liens entre artisanat et connaissance pratique, évolutions des constellations socio-politiques et réformes intellectuelles et religieuses.

57. Voir GULLBEKK, 2015. Gullbeck analyse le lien entre essor de l'économie monétaire et évolutions théologiques et intellectuelles dans la Norvège médiévale.

58. Voir, par exemple, TOURY, 1995.

59. HaRĐARSON, 2016, p. 42.

60. OMMUNDSEN, 2007.

61. Voir KARLSEN, 2013.

62. Pour une vue d'ensemble, voir LASSEN, 2017.

63. Voir aussi HARĐARSON, 2016, p. 36 ; GRØNLIE, 2017.

64. Voir, par exemple, RIKHARDSDOTTIR, (2012) 2017. Sur la " visière » d'Euphemia, voir FERM, HEDSTRÖM, LODÉN et al., 2015.

65. BANDLIEN, 2016.

66. BARNES, 2014.

67. Sur les intellectuelles et la recherche en Europe, voir WEI, 2014. Voir aussi les travaux sur la postérité de Brigitte menés par Roger Andersson, Unn Falkeid et Laura Saetveits Miles, cités n. 9.

68. FRIDRIKSDOTTIR, 2013. Le thème de la dernière réunion de la branche nordique de l'International Arthurian Society, qui s'est tenue à Trondheim les 13 et 14 septembre 2018, était « Arthurian Women. Mothers, Lovers and Others » (voir sur le site : http://www.internationalarthuriansociety.com/images/uploads/documents/CfP_Nordic Branch_of_the_International_Arthurian_Society.pdf).

69. KJESRUD, LØKKA, 2017.

70. Voir par exemple les travaux récents menés à l'université d'Oslo : Tiny Voices from the Past: New Perspectives on Childhood in Early Europe (https://www.hf.uio.no/ ifikk/english/research/projects/childhood/). Voir aussi la thèse en cours de rédaction de Rakel Igland Diesen à I'Université norvégienne des sciences et de la technologie sur les « Conceptions de l'enfance et de la jeunesse 
dans I'hagiographie médiévale nordique ", qui s'intéresse principalement aux vies de saints et aux récits de miracles en latin et en vieux norrois.

71. BANDLIEN, 2015 et 2018.

72. STANG, 2019.

73. Voir les recherches en cours de Jørn Sunde sur "Les Femmes, les enfants et les pauvres".

74. Voir les recherches de Pernille Hermann, par exemple HERMANN, MITCHELL, ARNÓRSDÓtTIR, 2014.

75. Glauser, HERMANN, MitCHeLl, 2018.

76. Voir les six volumes récemment parus de BROOMHALL, DAVIDSON, LYNCH, 2019.

77. BRANDSMA, LARRINGTON, SAUNDERS, 2018.

78. RIKARDSDOTTIR, 2017.

79. ERIKSEN, 2016.

80. Sur Snorri Struluson, voir SVEINBJARNARDÓtTIR, PORLÁKSSON, 2018 ; sur Sturla Pórðarson, voir SIGURĐSSON, JAKOBSSON, 2017.

\section{BIBLIOGRAPHIE}

-AAVITSLAND, 2019 : Kristin B. Aavitsland, "Civitas Hierusalem famosissima: The Cross, the Orb, and the History of Salvation in the Medieval North ", dans B. Aavitsland et Line Bonde (dir.), The Holy City: Tracing the Jerusalem Code, vol. 1. Christian Cultures in Medieval Scandinavia (ca 1100-1536), Berlin, De Gruyter, 2019, à paraître.

- ADAMS, 2016: Jonathan Adams, The Revelations of St Birgitta. A Study and Edition of the Birgittine-Norwegian Texts, Swedish National Archives E8902, Brill, 2016. - ANDÅS, EKROLL, HAUG et al., 2007 : Margrete Syrstad Andås, Øystein Ekroll, Andreas Haug et. al. (dir.), The Medieval Cathedral of Trondheim. Architectural and Ritual Constructions in their European Context, actes de colloque (Trondheim, Centre for medieval studies at the Norwegian University of science and technology, 2004), Turnhout, Brepols, 2007.

- ANDERSSON, 2012 : Theodor Andersson, The Patrisian Muse in Early Icelandic Sagas, Ithaca, Cornell University Press, 2012.

- ATtINGER, 2004 : Gisela Attinger, The Nidaros Office of the Holy Blood: Liturgical Music in Medieval Norway, Trondheim, Tapir akademisk forlag, 2004.

- BAGGE, 1976 : Sverre Bagge, Den kongelige kapellgeistlighet 1150-1319, Bergen, Universitetsforlaget, 1976. - BAGGE, 1984 : Sverre Bagge, "Nordic Students at Foreign Universities until 1600 », dans Scandinavian Journal of History, 1984, p. 1-29.

- BANDLIEN, 2015 : Bjørn Bandlien, "Trading with Saracens and the Sámi in medieval Norway ", dans Cordelia Hess et Jonathan Adams (dir.), Fear and Loathing in the North: Jews and Muslims in Medieval Scandinavia and the Baltic, Berlin, de Gruyter, 2015, p. 31-48.

- BANDLIEN, 2016 : Bjørn Bandlien, "A Manuscript of the Old French William of Tyre (Pal. Lat. 1963) in Norway", dans Studi mediolatini e volgari, n 62, 2016.
- BANDLIEN, 2018 : Bjørn Bandlien, « Images of Muslims in medieval Norway and Iceland ", dans Kurt Villads Jensen, Carsten Selch Jensen, et Janus Møller Jensen (dir.), Fighting for the Faith - The Many Crusades, Stockholm, Runica et mediaevalia, 2018, p. 96-137.

- BANDLIEN, à paraître : Bjørn Bandlien (dir.), Jerusalem Viken: Crusading, Ideology, Monasticism, and Politics in South-Eastern Norway, c. 1150-1220, actes de colloque (Oslo, Norwegian School of Theology, Religion and Society, 2017), à paraître.

- BARNES, 2014 : Geraldine Barnes, The Bookish Riddarasögur: Writing Romance in Late Medieval Iceland, Odense, University Press of Southern Denmark, 2014. - BARTLETT, 1993 : Robert Bartlett, The Making of Europe: Conquest, Colonization, and Cultural Change, 950-1350, Princeton, Princeton University Press, 1993. - BAUER, KLEIVANE et SPURKLAND, 2018 : Alessia Bauer, Elise Kleivane et Terje Spurkland (dir.), Epigraphy in an Intermedial Context, Dublin, Four Court Press, 2018. - Benham, 2016 : Jenny Benham, "Writing Peace, Writing War: Roger of Howden and Saxo Grammaticus Compared ", dans MÜNSTER-SWENDSEN, HEEBØLL-HOLM, SØNNESYN, 2016, p. 272-291.

- BERNHARĐSSON, 2016 : Haraldur Bernharðsson (dir.), Íslensk klausturmenning á miðöldum, Reykjavík, Miðaldastofa Háskóla Íslands, 2016.

- BOJE MORTENSEN, LEHTONEN, BERGHOLM, 2013 : Lars Boje Mortensen, Tuomas M. S. Lehtonen, avec Alexandra Bergholm (dir.) The Performance of Christian and Pagan Storyworlds. Non-Canonical Chapters of the History of Nordic Medieval Literature, Turnhout, Brepols, 2013. -BONDE, 2019 : Line Bonde, "Jerusalem Commonplace in Danish Romanesque Churches ", dans Kristin B. Aavitsland et Line Bonde (dir.), The Holy City: Tracing the Jerusalem Code, vol. 1. Christian Cultures in Medieval Scandinavia (ca 1100-1536), Berlin, De Gruyter, 2019. - BRANDSMA, LARRINGTON, SAUNDERS, 2018 : Frank Brandsma, Carolyne Larrington, Corinne Saunders (dir.), Emotions in Medieval Arthurian Literature: Body, Mind, Voice, Woodbridge, D.S. Brewer, 2018.

- BREGAINT, 2016 : David Bregaint, Vox Regis: Royal Communication in High Medieval Norway, Leyde, Brill, 2016. - BROOMHALL, DAvidSON, LYNCH, 2019 : Susan Broomhall, Jane W. Davidson, Andrew Lynch (dir.), A Cultural History of Emotions, Bloomsbury Academic, 2019.

\section{$\bullet$}

- CARRUTHERS, 1994 : Mary Carruthers, The Book of Memory. A Study of Memory in Medieval Culture, Cambridge, Cambridge University Press, 1994.

- CLUNIES ROSS, 1999 : Margaret Clunies Ross, « From Iceland to Norway: Essential Rites of Passage for an Early Icelandic Skald », dans alvíssmál, n 9, 1999, p. 55-72. - CLUNIES ROSS, 2018 : Margaret Clunies Ross, "The transmission and preservation of eddic poetry », dans Carolyne Larrington, Judy Quinn, Brittany Schorn (dir.), A Handbook to Eddic Poetry, Cambridge, Cambridge University Press, 2018, p. 12-32.

- COPELAND, 2005 : Rita Copeland, Pedagogy, Intellectuals, and Dissent in the Later Middle Ages, Cambridge, Cambridge University Press, 2005.

\section{$\bullet$}

- DRECHSLER, 2017 : Stefan Andreas Drechsler, Making Manuscripts at Helgafell in the Fourteenth Century, thèse de doctorat, University of Aberdeen, 2017. 
- EKROLL 2003 : Øystein Ekroll, «St. Olavs skrin i Nidaros », dans Steinar Imsen (dir.), Ecclesia Nidrosiensis 1153-1537. Søkelys på NIdaroskirkens og Nidarosprovinsens historie, Senter for Middelalderstudier, NTNU (Skrifter nr. 15), Tapir Akademisk Forlag, Trondheim, 2003, p. 325-352.

- ERIKSEN, 2014 : Stefka G. Eriksen, Writing and Reading in Medieval Manuscript Culture, Turnhout, Brepols, 2014.

- ERIKSEN, 2016 : Stefka G. Eriksen (dir.), Intellectual Culture in Medieval Scandinavia, c. 1100-1350, Turnhout, Brepols, 2016.

- ERIKSEN, 2018 : Stefka G. Eriksen, « 'Liquid Knowledge' in Old Norse Literature and Culture ", dans Viator, $\mathrm{n}^{\circ}$ 49, 2, 2018, à paraître.

- FERM, HEDSTRÖM, LODÉN et al., 2015 : Olle Ferm, Ingela Hedström, Sofia Lodén et al. (dir.), The " Eufemiavisor » and Courtly Culture: Time, Texts and Cultural Transfer, actes de colloque (Stockholm, 2012), Stockholm, Kungl. Vitterhetsakademien, 2015.

- FERM, KIHLMAN, 2011 : Olle Ferm et Erika Kihlman (dir.), Swedish Students at the University of Vienna in the Middle Ages, Stockholm, Centre for Medieval Studies, 2011.

- FOERSTER, 2016 : Thomas Foerster, «Ideas of Empire: Saxo Grammaticus and Godfrey of Viterbo ", dans MÜNSTER-SWENDSEN, HEEBØLL-HOLM, SøNNESYN, 2016, p. 252-271.

- FRIDRIKSDOTTIR, 2013 : Johanna Katrin Fridriksdottir, Women in Old Norse Literature: Bodies, Words, and Power, Basingstoke, Palgrave Macmillan, 2013.

- FRIIS-JENSEN, 1981 : Karsten Friis-Jensen (dir.), Medieval Author between Norse and Latin Culture, Copenhague, Museum Tusculanum Press, 1981.

- FRIIS-JENSEN, 1987 : Karsten Friis-Jensen, Saxo Grammaticus as Latin Poet. Studies in the Verse Passages of the Gesta Danorum, Analecta Romana Instituti Danici, Supplementa, 14, Rome, L'Erma di Bretschneider, 1987.

- GejRot, RisberG et ÅKestam, 2010 : Claes Gejrot, Sara Risberg et Mia Åkestam (dir.), Saint Birgitta, Syon and Vadstena, Stockholm, Kungl. Vitterhets historie och antikvitets akademien, 2010.

- GRøNLIE, 2017 : Siân E. Grønlie, The Saint and the Saga Hero. Hagiography and Early Icelandic Literature, Cambridge, Brewer, 2017.

- GULLBEKK, 2015 : Svein H. Gullbekk, "The Church and Money in Norway, c. 1050-1250: Salvation and Monetization », dans Giles E. M. Gasper et Svein H. Gullbekk (dir.), Money and the Church in Medieval Europe, 1000-1200. Practice, Morality and Thought, Londres/ New York, Routledge, 2015, p. 223-244.

- GUNNELL, 2008 : Terry Gunnell, The Origins of Drama in Scandinavia, Woolbridge, Suffolk, D. S. Brewer, 2008. - GUNNELL, LASSEN, 2013 : Terry Gunnell et Annette Lassen (dir.), The Nordic Apocalypse: Approaches to Völuspá and Nordic Days of Judgement, Turnhout, Brepols, 2013.

- HAGLAND, 1998 : Jan Ragnar Hagland, «Innskrifta på Kulisteinen. Ei nylesing ved hjelp av Jan O. H. Swantessons mikrokarteringsteknologi ", dans Audun Dybdahl, Jan Ragnar Hagland (dir.), Innskrifter og datering / Dating
Inscriptions, Trondheim, Tapir forlag (" Senter for middelalderstudier Skrifter », 8), 1998, p. 129-140.

- HARĐARDÓTTIR, 2016 : Guðrún Harðardóttir, « Myndefni íslenskra klausturinnsigla », dans BERNHARĐSSON, 2016, p. 201-226.

- HARĐARSON, 2016 : Gunnar Harðarson, « Old Norse Intellectual Culture: Appropriation and Innovation », dans ERIKSEN, 2016, p. 35-76.

- HAUGliG, 2016 : Kjartan Hauglig, " A Deliberate Style: The Patronage of Early Romanesque Architecture in Norway ", dans ERIKSEN, 2016, p. 103-136.

- HEINZ, 2019 : Katharina Heinz, Rhetoric in Medieval Manuscript and Text, thèse de doctorat, University of Oslo, 2019.

- HeRMANN, MitCHell, ARNÓRSDÓTtIR, 2014 : Pernille Hermann, Stephen A. Mitchell, Agnès S. Arnórsdóttir (dir.), "Minni » and "Munninn »: Memory in Medieval Nordic Culture, Turnhout, Brepols, 2014.

- HERMANNSSON, 1935 : Halldór Hermannsson, Icelandic Illuminated Manuscripts of the Middle Ages, Copenhagen, Levin \& Munksgaard, 1935.

- HOLMQVIST, 2018 : Karen Holmqvist, "Names and Prayers: Expressions of self in the Medieval Inscriptions of the Nidaros Cathedral Walls ", dans Collegium Medievale, 2018, p. 103-150.

- IMSEN, 2003 : Steinar Imsen (dir.), Ecclesia Nidrosiensis 1153-1537: søkelys på Nidaroskirkens og Nidarosprovinsens historie, Trondheim, Tapir akademisk forlag, 2003.

- JAEGER, 1994 (2013) : C. Stephen Jaeger, The Envy of Angels: Cathedral Schools and Social Ideals in Medieval Europe, 950-1200, Philadelphia, University of Pennsylvania Press, 1994 (2013).

- JAEGER, 2016 : C. Stephen Jaeger, « Dudo of St Quentin and Saxo Grammaticus: Historiography in Two Phases of Charismatic Culture », dans MÜNSTER-SWENDSEN, HEEBØLL-HOLM, SøNNESYN, 2016, p. 235-251.

- JOHANSSON, KLEIVANE, 2018 : Karl G. Johansson et Elise Kleivane (dir.) Speculum septentrionale. Konungs skuggsjá and the European Encyclopedia of the Middle Ages, Oslo, Novus, 2018.

- KäLLSTRÖM, 2012 : Magnus Källström, «Clerical or Lay Literacy in Late Viking Age Uppland? The Evidence of Local Rune Carvers and Their Work », dans Kristel Zilmer et Judith Jesch (dir.) Epigraphic Literacy and Christian Identity. Modes of Written Discourse in the Newly Christian European North, Turnhout, Brepols, 2012, p. 27-62.

- KARLSEN, 2013 : Espen Karlsen (dir.), Latin Manuscripts in Medieval Norway. Studies in Memory of Lilli Gjerløw, Oslo, Novus, 2013.

- KARLSSON, 2000: Gunnar Karlsson, The History of Iceland, Minneapolis, University of Minnesota Press, 2000. - KAUSLAND, 2016 : Kristin Kausland, Late Medieval Altarpieces in Norway - Domestic, Imported, or a Mixed Enterprise? An Art Technological Study of Northern German and Norwegian Altarpiece Production in the Period 1460-1530, thèse de doctorat, University of Oslo, 2016 - KJESRUD, LøKKA, 2017 : Karoline Kjesrud et Nanna Løkka (dir.), Dronningen i vikingtid og middelalder, Oslo, Scandinavian Academic Press, 2017. 
- KOLLANDSRUD, 2018 : Kaja Kollandsrud, Evoking the Divine: The Visual Vocabulary of Sacred Polychrome Wooden Sculpture in Norway between 1000 and 1350, thèse de doctorat, University of Oslo, 2018.

- KRISTJÁNSDÓTTIR, 2013 : Guðbjörg Kristjánsdóttir (dir.), Íslenska teiknibókin, Reykjavík, Crymogea, 2013. - KRISTJÁNSDÓTTIR, 2016 : Guðbjörg Kristjánsdóttir, " Handritalýsingar í benediktínarklaustrinu á Pingeyrum », dans BERNHARĐSSON, 2016, p. 227-312.

- KRISTJÁNSSON, 1996 : Jónas Kristjánsson, Icelandic Manuscripts: Sagas, History and Art, Reykjavík, Icelandic Literary Society, 1996.

\section{-}

- LASSEN, 2017 : Annette Lassen, «Indigenous and Latin Literature ", dans Ármann Jakobsson et Sverrir Jakobsson (dir.), The Routledge Research Companion to the Medieval Icelandic Saga, New York, Routledge, 2017, p. 74-87.

- LE GOFF, (1957) 1993 : Jacques Le Goff, Intellectuals in the Middle Ages, Teresa Lavender Fagan (trad. angl.), Cambridge, MA, Blackwell, 1993 [éd. orig. : Les Inte/lectuels au Moyen Âge, Paris, Éditions du Seuil, 1957]. - LIBERA, 1991 : Alain de Libera, Penser au Moyen Âge, Paris, Éditions Points, 1991.

- LIEPE, 2009 : Lena Liepe, Studies in Icelandic Fourteenth Century Book Painting, Reykholt, Snorrastofa, 2009.

- LÖNNROTH, 2017 : Harry Lönnroth (dir.), Philology Matters! Essays on the Art of Reading Slowly, Leyde, Brill, 2017.

- MÜNSTER-SWENDSEN, HEEBØLL-HOLM, SøNNESYN, 2016 : Mia Münster-Swendsen, Thomas K. HeebøllHolm, et Sigbjørn Olsen Sønnesyn (dir.), Historical and Intellectual Culture, Durham, Toronto Pontifical Institute of Medieval Studies, 2016.

- NILSÉN, 2014 : Anna Nilsén, The Gothic Sculpture of Uppsala Cathedral. On spiritual Guidance and Creative Joy, Turnhout, Brepols, 2014.

- NORDY, 2018 : Jonas Nordy, Lønnruner. Kryptografi i runeinnskrifter fra vikingtid og middelalder, thèse de doctorat, University of Oslo, 2018.

- Oen, SAHLIN, 2018 : Maria H. Oen, Claire L. Sahlin (dir.), A Companion to Birgitta of Sweden and Her Legacy in the Later Middle Ages, Leyde / Boston, Brill, 2018. - OMMUNDSEN, 2007 : Åslaug Ommundsen, Books, Scribes and Sequences in Medieval Norway, thèse de doctorat, University of Bergen, 2007.

\section{-}

- RANKOVIĆ, BrüGger Budal, CONTI, MELVE, MUNDAL, 2012 : Slavica Ranković, Ingvil Brügger Budal, Aidan Conti, Leidulf Melve et Else Mundal (dir.), Modes of Authorship in the Middle Ages, actes de colloque (Bergen, "Tradition and the Individual Talent: Modes of Autorship in the Middle Ages ", 2008), Toronto, Pontifical Institute of Medieval Studies, 2012.

- RANKOVIĆ, MELVE, MUNDAL, 2010 : Slavica Ranković, Leidulf Melve et Else Mundal (dir.), Along the Oral-Written Continuum. Types of Texts, Relations and their Implications, Turnhout, Brepols, 2010.

- RIKHARDSDOTTIR, (2012) 2017 : Sif Rikhardsdottir, Medieval Translations and Cultural Discourse (2012), Cambridge, Brewer, 2017.
- RIKHARDSDOTTIR, 2017 : Sif Rikhardsdottir, Emotion in Old Norse Literature. Translations, Voices, Contexts, Woodbridge, Boydell \& Brewer Ltd, 2017.

- ROHRBACH, 2014 : Lena Rohrbach (dir.), The Power of the Book. Medial Approaches to Medieval Nordic Legal Manuscripts, Berlin, Berlin Humboldt-Universität zu Bln Nordeuropa Inst, 2014.

- SALONEN, VILLADS JeNSEN et JØRGENSEN, 2013 : Kirsi Salonen, Kurt Villads Jensen et Torstein Jørgensen (dir.), Medieval Christianity in the North, Turnhout, Brepols, 2013.

- SiguRĐSSON, 2005 : Gísli Sigurðsson, "Orality and Literacy in the Sagas of Icelanders ", dans Rory McTurk (dir.), A Companion to Old-Norse Icelandic Literature and Culture, Malden, Blackwell Publishing, 2005, p. 285-293. - SIGURĐSSON, JAKOBSSON, 2017 : Jón Viðar Sigurðsson et Sverrir Jakobsson (dir.), Sturla Pórðarson. Skald. Chieftain and Lawman, Leiden, Brill, 2017.

-STANG, 2019 : Margrethe C. Stang, « Enemies of Christ in the Far North: Tales of Saracens, Jews and the Saami in Norwegian Medieval Paintings ", dans B. Aavitsland et Line Bonde (dir.), The Holy City: Tracing the Jerusalem Code, vol. 1. Christian Cultures in Medieval Scandinavia (c. 1100-1536), Berlin, De Gruyter, 2019, à paraître. -STREETON, KOLLANDSRUD, 2014 : Noëlle L. W. Streeton et Kaja Kollandsrud (dir.), Paint and Piety: Collected Essays on Medieval Painting and Polychrome Sculpture, London, Archetype Publications, 2014.

- SVEINBJARNARDÓTTIR, PORLÁKSSON, 2018 : Guðrún Sveinbjarnardóttir et Helgi Porláksson (dir.), Snorri Sturlusson and Reykholt. The Author and Magnate, his Life, Works and Environment at Reykholt in Iceland, Reykjavík, Museum Tusculanum Press, 2018.

\section{$\bullet$}

- TOURY, 1995 : Gideon Toury, Descriptive Translation Studies, Amsterdam, John Benjamins, 1995.

- WALKER BYNUM, 2011 : Caroline Walker Bynum, Christian Materiality. An Essay on Religion in Late Medieval Europe, New York, Zone books, 2011.

- WEl, 2014 : Ian P. Wei, Intellectual Culture in Medieval Paris, Cambridge, Cambridge University Press, 2014. - WELLENDORF, 2010 : Jonas Wellendorf, « The Interplay of Pagan and Christian Traditions in Icelandic Settlement Myths ", dans Journal of English and Germanic Philology, $\mathrm{n}^{\circ} 109,1,2010$, p. 1-21.

- WOLF, VAN DEUSEN, 2017 : Kirsten Wolf et Natalie M. Van Deusen, The Saints in Old Norse and Early Modern Icelandic Poetry, Toronto, University of Toronto Press, 2017.

- ZILMER, 2010 : Kristel Zilmer, "Viking Age Rune Stones in Scandinavia: The Interplay between Oral Monumentality and Commemorative Literacy ", dans Slavica Rankovic, Leidulf Melve et Else Mundal (dir.), Along the Oral-Written Continuum. Types of Texts, Relations and their Implications, Turnhout, Brepols, 2010, p. 135-162.

- PORLÁKSSON, 2005 : Helgi Porláksson (dir.), Church Centres in Iceland from the $11^{\text {th }}$ to the $13^{\text {th }}$ Century and their Parallels in Other Countries, Reykholt, 2005. 
-PORLÁKSSON, SIGURĐADÓTTIR, 2012 : Helgi Porláksson et Póra Björg Sigurðadóttir (dir.), From Nature to Script. Reykholt, Environment, Centre, and Manuscript Making, Reykholt, Snorrastoffa Rit, VII, 2012. 